\title{
Teachers' Perceptions about their Responsibility for what Pupils Do on Social Media
}

\author{
Elin Thunman, Marcus Persson and Johanna Lovén \\ Department of Sociology, Uppsala University \\ Uppsala, Sweden
}

\begin{abstract}
Contributing to the knowledge about teachers' educational use of social media, the aim of this article is to explore Swedish secondary school teachers' understanding of their duties of care and responsibilities for what pupils do on social media. The article draws on data from a mixed method study, consisting of an interview study and a national survey. The findings from the survey show that some groups of teachers are more likely than others to express responsibility for pupils, especially teachers who use many different social media, those who use them in contact with pupils, teachers working at private schools, and female teachers. The subjective experiences from the interviews are supported by the findings from the survey - indicating a correlation between social media usage and level of perceived responsibility. The more the teachers use social media, and thereby get access to more personal information about the pupils, the greater the likelihood that the teachers will perceive that they have some responsibility for what the pupils do on social media. The meaning of the findings is discussed in relation to the theory of caring ethics.
\end{abstract}

Keywords: Teachers; social media; responsibility; ethics of care.

\section{Introduction}

The topic of this article is teachers' perceptions about their ethical responsibility for what pupils do on social media. The issue of ethical responsibilities and the lack of clear addressees have been highlighted in relation to young social media users (Howard, 2013; Fox \& Bird, 2017). In most countries, young people are regarded as minors and are thereby viewed as having questionable decisionmaking capacity (Batchelor et al., 2012). The issue of responsibility is even more accentuated since young persons are very frequent social media users and rapidly adopt new, not necessarily well regulated social media. Social media risks for young persons have been highlighted on topics such as cyber bullying, disclosure of personal information, sexual harassment and racism (Juvonen \& Gross, 2008; Livingstone \& Brake, 2010; Ybarra \& Mitchell, 2008; Yilmaz, 2010). The school authorities, administration, and teachers are often assigned ethical 
responsibilities and duties of care, for example, with respect to cyber bullying (Hinduja \& Patchin, 2011; Shariff, 2005), or to teaching pupils netiquette and how to behave online (Howard, 2013). As teachers are in daily contact with pupils, these expectations are often directed towards them. The ethical implications of educational use of social media have given rise to public debates (Fox \& Bird, 2017), bringing about calls for the development of national codes of conduct for the teaching profession (e.g. Edwards \& Jones 2009; Helleve, Almås \& Bjørkelo, 2013; National Union of Teachers in Sweden, 2010). In their daily practice with pupils, teachers are required to apply what is prescribed in the curriculum. The Swedish compulsory school curriculum states that schools not only have an educational responsibility, but duties of care as well:

"Concern for the well-being and development of the individual should
permeate all school activity. No one should be subjected to
discrimination on the grounds of gender, ethnic affiliation, religion or
other belief system, transgender identity or its expression, sexual
orientation, age or functional impairment or other degrading treatment.
Such tendencies should be actively combated. Xenophobia and
intolerance must be confronted with knowledge, open discussion and
active measures." (Swedish National Agency for Education, 2016b, p. 9)

This broad statement does not specifically address the use of ICT or online communication with pupils. At present, there are no official guidelines or codes of conduct in the Swedish school system on how teachers should behave towards pupils on social media, or how they should act when faced with inappropriate behaviours and other ethical dilemmas. The general advice to teachers, formulated by the Teachers' Professional Ethics Council (2012), is to 'act as in real life'. However, social media have inherently boundary-blurring affordances and allows for greater insight into pupils' lives. Increased transparency and the availability of more information about pupils evoke questions about the possibilities for teachers to act (morally) as they would in 'real' (physical) life. Faced with this situation, it is of essence to turn to the teachers themselves and inquire about how they think and act regarding their responsibility for pupils when using social media. Therefore, the aim of this article is to explore Swedish teachers' understanding of their duties of care and responsibilities for what pupils do on social media. We ask two research questions:

- How do the teachers perceive their responsibility for what pupils are doing on social media?

- Are certain groups of teachers more likely to express responsibility for what pupils do on social media?

To answer these questions, the article draws on data from a mixed methods study. The first part of the study consists of an interview study with Swedish secondary school teachers, and the second part consists of a national survey of secondary school teachers' perceptions and use of social media. While the interview study primarily focuses on the first research question, the survey focuses on the second question by focusing on type of school (private or public), number of social media used, gender and age of the teachers, and whether or not 
the teachers are working as lead teachers. ${ }^{1}$ The findings will be discussed from an ethics of care perspective.

\section{The ethics of care}

Teaching is a moral activity requiring teachers to weigh the ethical implications of their behaviour. Every day, teachers confront a multitude of moral dilemmas (online or offline) that compel them to make critical choices (Lampert, 1985). In this regard, the issue of the teacher's responsibility for what pupils do on social media is not primarily educational; rather, it touches upon more elusive dimensions of the teaching profession where the focus is on relational practices that promote mutual recognition, growth, development, protection, and empowerment (Gordon, Benner \& Noddings, 1996; Owens \& Ennis, 2005; Thunman \& Persson, 2017).

The caring relation is based on the importance of the relationship and the empathetic receptiveness towards the other rather than abstract moral reasoning (Tirri \& Husu, 2002). According to Noddings (1984), every interaction at school gives the teacher an opportunity to enter into a caring relation. In each caring encounter, one can identify a 'one-caring' and a 'cared-for'. The basic assumption of Noddings' ethic of care is the reciprocal relationship between the 'one-caring' and the 'cared for'. In an educational setting, the teacher assumes the role of the one-caring while the pupils are those cared for. In this relationship, the one-caring teacher feels an obligation and a sense of 'I must' in establishing the caring ethic. As Noddings (1992) explains, teachers who profess an ethic of care in their practice view themselves as the ones responsible for empowering their pupils. The caring ethic suggests that teachers approach pupils' needs from the subjective perspective of 'I must do something', rather than taking the more objective 'something must be done' approach. Teachers are motivated by this philosophy to perform conscious acts of 'being with' and 'doing for' for the sake of their pupils. This can be contrasted with leaving the responsibility for pupils' care to others and not taking any personal responsibility.

The ethic of care is often described as a 'feminine' ethic, based on an inductive and emotional logic rather than on a deductive and mathematical logic. Gilligan (1982) developed the ideas about responsibility-oriented morals, that is, values and moral commitments that focus on caring for and openness to the needs of others. The responsibility-oriented morals are different from a rights-oriented morality, primarily associated with men. Historically, responsibility morals, which have primarily been associated with women, have been misunderstood and neglected (Gilligan, 1982).

In this article, the concepts of ethics of care and responsibility-oriented morals, is used to interpret the teachers' understandings and expressions of their duties

1 The Swedish lead teacher reform was initiated in 2013 and is a career step for teachers who want to take on a leading role in the development of the organization and educational work (Swedish National Agency for Education, 2015). 
and responsibilities for what their pupils do on social media. The gendered aspect of the care ethics will be of special interest when exploring whether a certain group of teachers is more likely than others to take a greater responsibility.

\section{Methods}

Sweden is an Internet-dense country where access to the Internet is widespread among all ages (Findahl \& Davidsson, 2015). Swedish teachers are an occupational group that has been particularly quick to integrate Information and Communication Technologies (ICTs) and social media as work tools (Thunman \& Persson, 2013; European School net, 2013; National Union of Teachers in Sweden, 2010; Swedish National Agency for Education, 2016a). This makes Swedish secondary school teachers a fruitful departure point for studying teachers' responsibilities for what pupils do on social media.

The study is limited to secondary school teachers (K 7-9); as it is when they reach secondary school that many pupils first begin to use social media (Findahl \& Davidsson 2015). The fact that the pupils are underage (age 13-15) puts the ethical issues at the forefront for this particular teacher group.

As indicated above, this article builds on a mixed method design consisting of an interview study and a survey. The qualitative part was conducted first in order to explore teachers' experiences of using social media for pupil contact and to identify key issues for the teachers. Building on the findings from the interviews, the second study consists of a nationwide survey among teachers.

The study proposal has been approved by the regional ethical board in Uppsala $(2014 / 202)$, and informed consent was obtained from all participating teachers. Regarding the qualitative study, informed consent was obtained before the interviews were conducted. Regarding the quantitative study, informed consent was obtained together with the submitted answers.

\section{The interviews}

Six group interviews were conducted with secondary school teachers in four schools which are profiled as ICT-mature schools. In total, 25 teachers (15 women and 10 men between the ages of 25 and 65) with extensive experience of using ICTs and social media, particularly Facebook, in their work were recruited and interviewed.

The group interviews were conducted with four to six participants in each group. The interviews lasted one to two hours and took place in the participants' workplace, that is, at school, in late afternoons when the pupils had left. The interviews took place at school partly for practical reasons - being convenient for the teachers - but also because the teachers were likely to feel comfortable and relaxed doing the interviews in their familiar work setting (Hammersley \& Atkinson 1983). The group interviews were prompted with pre-specified topics, and open-ended questions allowed the discussion to evolve around these openended questions, facilitating interaction among the participants. This process 
allows participants to interject their own observations and understandings while also feeding off the ideas of other participants (Frey \& Fontana, 1991). The reason for conducting the interviews in groups, and not individually, was to create a stimulating conversation in which the participants could share their experiences and encourage each other to share theirs (Merton, Fiske \& Kendall, 1990) and, by doing so, give the researchers rich insights into the situations, dilemmas, and issues that teachers are facing when they use social media in interaction with pupils.

The pre-specified topics in the interview guide included 'use of social media services' (questions about the teachers' social media use for educational purposes), 'availability' (questions about the teachers' felt demands of being available for pupils' on social media), 'transparency and integrity' (questions about the teachers' sharing of private and professional information on social media and their thoughts about the increased insight into the pupils' private lives through social media), and 'responsibility' (questions about professional responsibilities for pupils' on social media and how to act when confronted with improper conduct).

The interviews with the teachers were audio recorded, and the interpretation process started with transcribing the recordings. Thereafter, the transcriptions were read several times within an extended timeframe and we took note of illustrative quotes. The teachers' accounts of their actions were collated into potential themes of interest for the aim of the study (Braun \& Clarke, 2006). In particular, we observed how the teachers talked about ethical dilemmas, feelings of responsibility, and their thoughts about their duties of care for pupils online as well as offline.

\section{The survey}

The survey was developed based on the findings from the interviews. The four topics in the interview guide were transformed into three topics: 'use of social media services' (questions about the teachers' use of specific social media services for different purposes in different situations), 'availability' (questions about when and where different social media services are used in contact with pupils), and 'responsibility' (questions about ethical guidelines and personal standards regarding un-/acceptable online conduct, teaching netiquette, and how the teachers act when confronted with improper conduct). In total, the questionnaire included 27 questions.

The survey was administered by Statistics Sweden and was distributed (both web-based and paper-based) on the $6^{\text {th }}$ of October 2015, and the data collection was finished on the $1^{\text {st }}$ of December 2015. The population consisted of certified teachers who were working in Swedish secondary schools. The sampling frame was based on data from the registry of pedagogical staff, which comprised 21334 persons (15 October 2014, Statistics Sweden). A stratified random sample was drawn from the sampling frame. The strata were based on gender and age (see Table 1). The sample consisted of 4000 teachers. Of these, only 2008 responded to the survey. 
Table 1. Response rate and number of respondents $(n)$ in each stratum.

\begin{tabular}{llrr}
\hline Stratum & & Response rate & $n$ \\
\hline Women & $\leq 40$ years & $47 \%$ & 304 \\
& $41-50$ years & $48 \%$ & 318 \\
& $\geq 51$ years & $61 \%$ & 393 \\
\multirow{3}{*}{ Men } & $\leq 40$ years & $40 \%$ & 251 \\
& $41-50$ years & $44 \%$ & 271 \\
& $\geq 51$ years & $50 \%$ & 309 \\
\hline All & & $50 \%$ & 2008 \\
\hline
\end{tabular}

There were 1834 participants who met the inclusion criteria of the present study: $55 \%$ of the teachers were women, and $45 \%$ were men; $87 \%$ were employed by a municipality or the state, and $12 \%$ were employed by a private school; and $17 \%$ worked as lead teachers.

To guide the main model of interest, that is, where differences in the teachers' expressed responsibility were investigated, we tested whether there were differences among the teachers in terms of the probability of their using social media for pupil contact. Logistic regression was used, and predictors were gender, age, school type (private or public state school), having a position as a lead teacher, and use of social media. Continuous variables (age, number of social media used) were mean centred. Logistic regression was also used to investigate whether there were differences in background characteristics between teachers who think that they have a responsibility for what pupils do on social media and those who do not think so. The background characteristics that were included were gender, age, school type (private or public state school), having a position as a lead teacher, and use of social media.

\section{Findings}

In the following sections, we present the findings from the qualitative and quantitative studies. We begin by looking at the teachers' subjective understanding of responsibility for what pupils do on social media. Thereafter, we account for how different groups of teachers perceive responsibility.

\section{Interviews: Transparency and different views on responsibility}

All interviewed teachers use social media in their work and for communication with pupils. A common reason, stated by the teachers, for using social media for pupil contact is the possibility to inform and contact pupils in a flexible way.

"We started the Facebook group because we thought, like, 'where are the pupils?' They have Facebook, so we will be able to reach out to them quickly." (Donna)

A main area of use among the teachers, is as 'news channel', to provide information about school assignments, events, advise of changes in schedules, and post various reminders. Social media can also be used as an educational tool in various schoolwork and projects. As Irene explains, describing a school project involving Facebook: 
"The topic of the project was teenage ideals. Teenagers do sometimes find it hard to talk in front of others, so we divided them into smaller groups, with their own chat rooms, where they discussed questions related to the project. Later, all groups presented their written answers in the class, and the pupils from the other groups wrote comments and questions. It turned into a written dialogue, where pupils, who otherwise are not that talkative, became engaged and took part in the discussion."

Social media are not only used for educational purposes but also for social. A large part of the communication between teachers and pupils on social media consists of small talks, jokes, and posts about things happening in or outside of school. To use social media in this way to create interaction and building good relationship with pupils are advocated by the teachers, as prerequisites for pupils' learning and development, as Anna and Christine discuss below.

Anna: "We also use it [Facebook] to have fun, joking and chatting with each other. It is not always about school."

Christine: "It is important to have good relations with pupils, and show them that we are here, that we see them. It's about confirmation, really."

Teachers' use of social media gives rise to increased information about the pupils' private lives, such as what they do on weekends and outside of school hours. Listening to the teachers, it is evident that they think a lot about the risks and problematic situations that they are facing when using social media. In the interviews, the teachers talk about moral dilemmas related to the increased transparency in the pupils' private lives, inappropriate behaviour of minors, and how to react when they see evidence of such conduct.

"If I read something on their Facebook, I do not know anything about it. I do not tell anybody about it. I'll keep it to myself. But yes, it might confirm my thoughts that I already had about the pupil, a bit like that. But I do not use that information for anything when I'm talking to colleagues or parents." (Mary)

The teachers can be witnesses to different kinds of information, or rather, information of different degrees of unsuitability. For example - as Bruce expresses in the quotation below - how should the teachers react if they notice on social media that pupils are doing something that is seen as inappropriate?

"There were some teachers here [at school] who have Facebook and discovered that the pupils decided to have a party, and it was obvious that these pupils were going to drink alcohol. In those situations, we do not have any guidance on what we should do." (Bruce)

The interviewed teachers also talk about situations in which social media were used as a digital arena and tool for inappropriate behaviour, such as harassment or bullying other pupils. 
"Conflicts might not necessarily occur here [at school], but they solve them here, because this is the only time you meet IRL, so to speak. Quite often, we trace the conflict back to what someone has written on Ask, and all those kinds of things, like they do at home. So it's like, it's changed. Bullying is behind screens today, more than it is face to face." (Jenny)

When the teachers talk about their professional responsibility they tend to compare physical and virtual situations in which they feel responsible for what the pupils are doing. For example, in one of the group interviews the teachers discuss how they act if they come across drunk pupils outside school hours. Jim and Linda say:

Jim: "If I go downtown on a Friday night, perhaps to the movies with my wife, and I see some of my pupils intoxicated, sitting on a park bench, then of course I am still a teacher, right? I feel the same thing regarding social media. If I see a pupil who is high as a kite on a Saturday evening, then of course I am still a teacher. I cannot turn a blind eye to things like that."

Linda: "It's the same as if you were to see a pupil standing in the schoolyard smoking, then I would report it to the parent. If I see a posted photo on Facebook of some pupil sitting with a beer bottle, I would do the same - contact those parents."

As evident in both Jim's and Linda's answers, they seem to act in line with the advice of the Teachers' Professional Ethics Council, to 'act as in real life' and to treat physical and virtual situations as equivalent in terms of their responsibility for what pupils do. However, not all of the interviewed teachers share this understanding of how far their online responsibility extends when comparing physical and virtual situations, as Harold says:

"Actually, I think you act differently. If you run into a drunk pupil on the town, then you stand right there with the problem - or situation - in front of you. Then I would probably act in a completely different way than I would if I were to see drunk pupils on Facebook, because that is something that has probably already happened or passed. If I were to run into a drunk pupil in town, I would probably call home to his or her parents, or at least contact some field assistant, or whatever, and ask them to take over."

According to Harold, there are limits to a teacher's responsibility for the pupils. He does not consider himself responsible for his pupils all the time in all kinds of situations - especially not in those situations seen on social media, where the event has already happened.

Other teachers go even further and use different strategies to avoid being witness to situations that could potentially demand some moral action by themselves. Teachers may, for example, separate between private and professional accounts, and thereby delimit their access to the pupils' online 
behaviour. As Jenny, who is selective about her use of social media services for private and professional use, says:

"I get a lot of requests [from pupils] on Instagram. I usually decline such requests. I do not really want to see everything that they do. I do not want to see when they are lying drunk in the gutter."

To sum up this far, there are differences among the teachers with respect to their understanding of their professional role and caring responsibility for what pupils do on social media. While, for example, Jim and Linda talk about equal responsibilities for pupils online and offline, Harold and Jenny emphasize limits and boundaries regarding communication and responsibility for what pupils do on social media. The differences in teachers' perceptions about responsibility are explored further in the next section when looking at differences between groups of teachers.

\section{Survey: Perceptions of responsibility among different groups of teachers}

Almost all participating secondary school teachers (92\%) report that they use at least one type of social media, either privately or professionally. Approximately one-third $(32 \%)$ of the teachers report that they use social media in contact with pupils. The observed proportion of teachers using social media for pupil contact is in line with the Swedish National Agency for Education (2016a) study about teachers' use of ICT.

The most commonly used social media among the teachers are YouTube $(77 \%)$, Facebook (65\%), Google+ (35\%), and Instagram (32\%). Fewer teachers report that they read or write blogs $(23 \%)$, or use Twitter $(13 \%)$ or Snapchat $(8 \%)$. These social media are used by the teachers for educational purposes to share information of various kinds, such as lesson materials and school assignments, or to discuss school-related issues. Social media are also used for social purposes, small talks, and to have fun, for example, by posting funny pictures or video clips (Thunman, Lovén \& Persson, 2016).

Looking at background characteristics, we see in Table 2 how women $(p=0.03)$ and teachers who use a larger number of social media (private or professional) $(p=<.001)$ are the two groups that are the most likely to use social media for pupil contact. Neither school type and teacher age, nor working as lead teacher indicates any significant relation with the dependent variable (probability of using social media in contact with pupils).

The correlation between 'number of social media used' and 'using social media for pupil contact' probably means that the teachers who use several or many different social media services are also the most likely to interact with pupils on social media.

The correlation between 'gender' and 'using social media for pupil contact' is possibly a reflection of a general pattern of behaviour. According to the results from the latest survey by Internet Statistics in Sweden (Findahl \& Davidsson, 2015), the extent of women's and men's use of social media is relatively even, but women are consistently more frequent visitors to social media and more 
active writers than men. The female tendency to adopt social media is as visible in the general population as it is among the teachers.

Table 2. The probability of using social media for pupil contact.

\begin{tabular}{lccccc}
\hline Parameter & $B$ & $S E$ & Wald $\chi^{2}$ & $p$ & $\operatorname{Exp}(B)$ \\
\hline Intercept & -1.22 & 0.17 & 51.81 & & 0.29 \\
School (public) & 0.19 & 0.17 & 1.31 & .25 & 1.21 \\
Position (lead teacher) & 0.20 & 0.14 & 2.10 & .15 & 1.22 \\
Gender (woman) & 0.24 & 0.11 & 4.94 & .03 & 1.27 \\
Age & 0.01 & 0.01 & 2.39 & .12 & 1.01 \\
Number of social media & 0.35 & 0.03 & 105.28 & $<.001$ & 1.43 \\
\hline
\end{tabular}

Cox and Snell $R^{2}=.07$, Nagelkerke $R^{2}=.10$.

Next, we will see if the female teachers' greater use of social media for pupil contact is reflected in the teachers' perception of their responsibility for what pupils do on social media. Logistic regression is used to investigate whether there are differences in background characteristics between those who think that teachers have responsibility for what pupils do on social media and those who do not think they have any responsibility. The predictors are gender, age, school type (private or public school), having a position as a lead teacher, and use of social media privately and as work tools for pupil contact. The results are presented in Table 3.

Table 3. The probability to be in the group that responded that teachers have responsibility for what pupils do on social media.

\begin{tabular}{llllll}
\hline Parameter & $B$ & $S E$ & Wald $\chi^{2}$ & $p$ & $\operatorname{Exp}(B)$ \\
\hline Intercept & 1.58 & 0.12 & 168.32 & & \\
Age & -0.01 & 0.01 & 1.20 & 0.27 & 0.99 \\
Number of social media & 0.13 & 0.05 & 7.64 & 0.01 & 1.14 \\
Gender (woman) & 0.03 & 0.07 & 0.18 & 0.67 & 1.03 \\
School (public) & -0.22 & 0.10 & 5.16 & 0.02 & 0.80 \\
Position (lead teacher) & 0.06 & 0.08 & 0.59 & 0.44 & 1.07 \\
Uses social media in education (yes) & 0.34 & 0.08 & 20.38 & $<.001$ & 1.41 \\
Gender $\times$ uses social media as work tool & -0.17 & 0.07 & 5.46 & 0.02 & 0.84 \\
Number of social media $\times$ & & & & & \\
uses social media as work tool & 0.002 & 0.05 & 0.00 & 0.96 & 1.00 \\
\hline
\end{tabular}

Cox and Snell $R^{2}=.04$, Nagelkerke $R^{2}=.06$

Three predictors of responsibility are significant: the number of social media the teachers use, whether the teachers work at a public or a private school, and whether the teachers use social media in their contact with pupils. These groups of teachers are more likely than other groups to express responsibility for the pupils.

Teachers who 'use social media for pupil contact' and those who use 'several' social media services are more likely to belong to the group expressing responsibility for pupils. Put differently, active teachers who are using social media for pupil contact are more likely to express responsibility for what pupils do on social media. 
Teachers' perception of responsibility is also related to whether the teachers work at a public or a private school, as teachers working at private schools are more likely to report that they have a responsibility for what pupils do on social media.

Even though female teachers are more likely to use social media than male teachers, as seen in Table 2, the relation between gender and perceived responsibility is not significant. To better understand the discrepancy between the teachers' actions and their perceptions, we investigate whether gender, and number of social media that teachers use, interact with their use of social media for pupil contact in ways that affect teachers' perceptions of responsibility for pupils' behaviour on social media.

When including interaction terms between gender and use of social media in education, and number of social media used and use of social media in education, only the interaction including gender is overall significant (-2 Log Likelihood $=2684, p=0.02$ ). The fact that gender in itself is not significant in relation to perceptions of responsibility but is significant when interacting with the variable 'using social media for pupil contact indicates a complex interaction between gender, social media use, and perceived responsibility.

As presented in Table 4, men who use social media as work tools for pupil contact are more likely to answer that they think teachers have a responsibility for what pupils do on social media. A similar relation is present for women, although the difference in perceived responsibility is not as large as for men. In fact, the female teachers are more likely to report that they perceive responsibility for what pupils do on social media regardless if they use social media or not. The level of perceived responsibility was high either way. On the contrary, we see a big gap between perceived responsibility among the male teachers who use, and do not use social media. Male social media users are more likely to express responsibility than male teachers who do not use social media.

Table 4. Predicted probability of agreeing with the notion that teachers have a responsibility for what pupils do on social media.

\begin{tabular}{ll}
\hline Gender and social media use in education & $p$ \\
\hline Woman, uses social media in education & .84 \\
Man, uses social media in education & .87 \\
Woman, does not use social media in education & .77 \\
Man, does not use social media in education & .68 \\
\hline
\end{tabular}

To sum up the findings, we have shown how perceptions of responsibility differ between teachers who believe that they take equal responsibility for pupils' well-being whether they act online or offline and those teachers who do not think they have, or want, such an equal responsibility. We have also observed that some groups of teachers are more likely than others to express responsibility for pupils, especially teachers who use many different social media, those who use them in contact with pupils, and female teachers. 


\section{Discussion: Transparency, responsibility, and gender}

Teachers may have different reasons for engaging with pupils through social media. They may use it as an information channel to reach out with news to the pupils quickly, as Jenny does, or they may use social media in more communicative ways, as Christine does, to cultivate good relations with the pupils by engaging in discussion, small talk, and jokes. From an ethics of care perspective, the teachers' ways of using social media can be understood as different expressions of a desire to 'be there' with the pupils and to try 'to do' something for them. Noddings (1992) explain that teachers who profess an ethic of care in their practice view themselves as responsible for empowering their pupils. The caring ethic suggests that teachers approach pupils' needs from the subjective perspective of 'being with' and 'doing something', rather than the more objective 'something must be done' approach, leaving pupils care up to others and removing themselves from personal responsibility.

However, the teachers' understanding of their duties of care is challenged by the increased transparency of the pupils' lives that social media brings about. Listening to the teachers, it is obvious that they from time to time come across expressions of inappropriate behaviour or unwanted information about the pupils. Such as when Mary is confronted with personal and sensitive information about a pupil through social media, or when Bruce discover, through social media, that his minor pupils are planning a party where alcohol will be served. Social media tends to blur the boundaries between public and private domains. When teachers start to use social media in contact with pupils, they also get a glimpse into the private lives of the pupils. The teachers may be confronted with information and behavior that they deem immoral or questionable. The interviews show that faced with the situation, the teachers need to reflect on personal and professional standards regarding responsibility, and ultimately choose whether to act on the information or not.

That social media use for pupil contact correlate with perceived responsibility is supported by the findings from the survey, indicating a correlation between frequency of social media usage, number of social media used, and level of perceived responsibility among the teachers in the study. Put differently, the more the teachers use social media, and thereby get access to personal information about the pupils, the greater is the likelihood that the teachers will perceive that they have responsibility for what the pupils do on social media. In our understanding, increased insight into the private lives of pupils through social media might evoke teachers' perceptions about duties of care. Following that line of thought, it makes sense to do as Harold and Jenny, i.e. if you do not want responsibility for pupils on social media, it is rational to delimit the insight into the pupils' private lives. Otherwise you may feel obligated to try 'to do' something.

In the survey, we also saw a relationship between gender and responsibility. Whether they use social media or not, female teachers are more likely to report that they feel that they have responsibility for what pupils do on social media. Gilligan's (1982) ideas about traditional 'female' responsibility-oriented morals, 
that is, values and moral commitments that focus on caring for and openness to the needs of others, could help explain female teachers' generally higher likelihood of perceiving responsibility. As an expression of a lived female role as care provider, who's self value depends on affinity and caring relationships to others (Gilligan, 1982), female teachers in general are, so to speak, already practising a caring ethic and are not affected by the increased insight into the private lives of the pupils that social media brings about.

Gilligan's ideas could also help explain male teachers' lower likelihood of perceiving responsibility since a traditional male role is not primarily based on caring principles, but rather on moral principles about justice. While caring ethics are often associated to 'feminine' values and ways of being, justice ethics are often associated to 'masculine' values and ways of being. Contrary to a caring ethics, the justice ethics are founded on a sense of separation that can be understood as a way of being with others that allows one also to be with oneself. Justice ethics promotes individuality and autonomy, and view dependency as a hinder for individual self-realization (Gilligan, 1982). The connection between ethics and sex is - according to Gilligan (1995) - developed in early childhood through the internalization of the interpretive framework of patriarchy that outlines what it means to be a girl or a boy. Although, the concepts of caring ethics and justice ethics is associated to gendered ways of being, it does not mean that all women adopt a caring ethics, or that all men adopt a justice ethics. In fact, in our interview data, we see how both female and male teachers express various ways of being that can be interpreted as caring ethics. For example, both Jim and Linda consider, as reflected in the quotations above, themselves having the same level of responsibility for the pupils, whether it is in school, outside school hours, or on social media.

In addition, it is evident that both female and male teachers express signs of justice ethics in regard to their pupil contacts on social media. For example, Harold's and Jenny's reluctance to take the same level of responsibility for pupils as Jim and Linda, may be understood as a strategy that promotes separation between private and work domains. In the private domain, or role, Harold and Jenny advocate the right to autonomy, individual freedom, and the absence of personal responsibility for pupils. Harold and Jenny are using social media for pupil contacts, and they do express ambition of 'being with' the pupils. However, their relationship with, and responsibility for the pupils are not boundless and infinite, but regulated according to a separating way of being.

With that in mind, it is interesting to observe that, according to the survey results, the male teachers who use social media for pupil contact are the ones who are the most likely to perceive responsibility for what the pupils do on social media. The sense of responsibility in this group is even higher than for the female teachers who use social media. Why is the sense of responsibility the highest for this group of teachers? There are two possible answers.

The first answer rests on causation between ethics and use of social media, i.e. that it is the teachers that practise caring ethics that are using social media. 
Following Gilligan's line of thought, the answer would explain why the use of social media does not have the same effect among female teachers since women in general tend to be practicing caring ethics. However, the answer would also imply that there are exceptionally many male teachers in Sweden that have adopted caring ethics.

The second answer rests on an idea about an opposite causation, namely that social media contacts with pupils make the male teachers more caring. Because female teachers tend to be practising caring ethics already - following Gilligan's line of thought - the increased insight into pupils' private lives through social media would not create the same effect on the female teachers' sense of responsibility as it would on male teachers', who instead tend to be practising justice ethics. Put differently, the insight into pupils' private lives may have the biggest effect on those teachers with the least experience of using social media for pupil contact. Having argued that the use of social media may increase the possibility of 'being with' the pupils, the gap in perceived responsibility between male teachers who use, and not use, social media for pupil contacts, may be understood as a result of the moral dilemmas that follow from the increased insights into the pupils' private lives. The answer is interesting since it implies that the use of social media for pupil contact could promote a transformation from a justice ethics towards a caring ethics.

\section{Limitations and future research}

There are some limitations of the study. Since this study was carried out in Sweden, the relevance of the results may be limited to this particular context, and there may be differences between countries regarding teachers' use of social media and their perceptions of ethical responsibilities. Therefore, we would like to draw attention to the need for studies of teachers from different socio-cultural and geographical contexts, as well as to the need for studies of teachers operating at different levels of education.

Another limitation of the study is the absence of the pupil perspective. Previous research has explored pupils' perceptions about the teacher role and teachers' disclosure when teachers use social media in contact with pupils (e.g. Mazer et al., 2009). However, there is a lack of research about pupils' understanding about the teacher role and teachers' ethical responsibility when using social media for pupil contacts. Thus, we suggest that future research include the pupil perspective in order to get a comprehensive understanding of teachers' and pupils' perceptions about teachers' responsibilities when using social media for educational purposes.

\section{Conclusion and implications}

The aim of this article was to explore teachers' understanding of their duties of care and ethical responsibilities for what pupils do on social media. The main conclusion is that there is a relationship between social media usage and level of perceived responsibility. The more a teacher use social media, and thereby get access to more personal information about the pupils, the greater the likelihood 
that the teacher experiences responsibility for what the pupils do on social media.

A related conclusion concerns the gender of the teachers. Generally speaking, the identified relationship between social media usage and level of perceived ethical responsibility is most prominent in the case of male teachers. Female teachers are instead inclined to experience responsibility for pupils, regardless of whether they use social media for pupil contacts or not. The identified gender differences have been elucidated with the help of the theory of caring ethics.

The identified differences between teacher groups regarding their perceived ethical responsibility for what pupils do on social media call for the need of policy making on different levels. On a macro level, the result indicates a need for national guidelines or codes of conduct for teacher use of social media. On a meso level, there is a need for the establishment of school management standards. The current lack of both national and organisational guidelines has implications on a micro level. Without guidelines, it becomes the individual teacher's task to decide how to think and act in relation to pupils on social media. As evident in quotes in this study, teachers may face ethical dilemmas when encountering pupils on social media and the solution of how to act in a professional and ethical manner in certain situations is not always obvious. An establishment of guidelines would help the individual teacher in these situations. In addition, such guidelines could help pupils to better understand what to expect of teachers on social media.

\section{Acknowledgments}

The Swedish Research Council for Health, Working Life and Welfare (FORTE) supported this work (grant number 2013-0451).

\section{References}

Batchelor, R., Bobrowicz, A. Mackenzie, R., \& Milne, A. (2012). Challenges of ethical and legal responsibilities when technologies' uses and users change: Social networking sites, decision-making capacity and dementia. Ethics and Information Technology, 14, 99-108. https://doi.org/10.1007/s10676-012-9286-x

Braun, V., \& Clarke, V. (2006). Using thematic analysis in psychology. Qualitative Research in Psychology, 3(2), 77-101. https://doi.org/10.1191/1478088706qp063oa

Edwards, C., \& Jones, F. (2009). Is my profile open? When teachers post 'inappropriate' material on social networking sites, The Berkeley Electronic Press. Retrieved from: http:// works.bepress.com/cgi/viewcontent. cgi? article $=1000 \&$ context $=$ faye_jones

European Schoolnet (2013). Survey of schools: ICT in education. Benchmarking access, use and attitudes to technology in Europe's schools. Final Study Report. Retrieved from: https://ec.europa.eu/digital-single-market/sites/digital-agenda/files/KK-3113-401-EN-N.pdf

Findahl, O., \& Davidsson, P. (2015). Svenskarna och internet 2015 [The Swedes and Internet 2015]. Stockholm: The Internet foundation in Sweden.

Fox, A., \& Bird, T. (2017). The challenge to professionals of using social media: Teachers in England negotiating personal-professional identities. Education and Information Technology, 22(2), 647-675. https://doi10.1007/s10639-015-9442-0 
Frey, J. H., \& Fontana, A. (1991). The group interview in social research. The Social Science Journal, 28(2), 175-187. https:// doi.org/10.1016/0362-3319(91)90003-m

Gilligan, C. (1982). In a different voice: Psychological theory and women's development. Cambridge, MA: Harvard University Press.

Gilligan, C. (1995). Hearing the Difference: Theorizing Connection. Hypatia, 10(2), 120127. https:// doi.org/10.1111/j.1527-2001.1995.tb01373.x

Gordon, S., Benner, P., \& Noddings, N. (Eds.) (1996). Caregiving: Readings in knowledge, practice, ethics, and politics. Philadelphia: University of Pennsylvania Press.

Hammersley, M., \& Atkinson, P. (1983). Ethnography: Principles in practice. London: Tavistock.

Helleve, I., Almås, A. G., \& Bjørkelo, B. D. (2013). Social networking sites in education:Governmental recommendations and actual use. Nordic Journal of Digital Literacy, 04, 192-207. Retrieved from: http://www.idunn.no/ts/dk/2013/04/social_networking_sites_in_education_ governmental_recomme? mostRead=true

Hinduja, S., \& Patchin, J. W. (2011). Cyber bullying: A review of the legal issues facing educators. Preventing school failure: Alternative education for children and youth, 55(2), 71-78. https:// doi.org/10.1080/1045988x.2011.539433

Howard, K. E. (2013). Using Facebook and other SNSs in k-12 classrooms: Ethical considerations for safe social networking. Issues in Teacher Education, 22(2), 39-54. Retrieved from: $\mathrm{http}: / /$ digitalcommons.chapman.edu/education_articles/50

Juvonen, J., \& Gross, E. F. (2008). Extending the school grounds? Bullying experiences in cyberspace. Journal of School Health, 78(9), 496-505. https://doi.org/10.1111/j.1746-1561.2008.00335.x

Lampert, M. (1985). How do teachers manage to teach? Perspectives on problems in practice. Harvard Educational Review, 55, 178-194. https://doi.org/10.17763/haer.55.2.56142234616×4352

Livingstone, S., \& Brake, D. R. (2010). On the rapid rise of social networking sites: New findings and policy implications. Children \& Society, 24(1), 75-83. https://doi:10.1111/j.1099-0860.2009.00243.x

Mazer, J. P., Murphy, R. E. \& Simonds, C. J. (2009). The effects of teacher selfdisclosure via Facebook on teacher credibility, Learning, Media and Technology 34(2), 175-83. https://doi.org/10.1080/17439880902923655

Merton, R. K., Fiske, M., \& Kendall, P. L. (1990). The focused interview: A manual of problems and procedures. [1956] New York: The Free Press.

National Union of Teachers in Sweden. (2010). Elever och lärare online: Var går gränsen? [Pupils and Teachers Online: Where Is the Line?]. Stockholm: Author. Retrieved from:

https://www.lr.se/opinionpaverkan/undersokningar/arkiv/eleverochlarareon linevargargransen.5.4ff660ce12b12fe7dbb80003297.html

Noddings, N. (1984). Caring: A feminine approach to ethics \& moral education. Los Angeles: University of California Press.

Noddings, N. (1992). The challenge to care in schools. New York: Teachers College Press.

Owens, L. M. \& Ennis, C. D. (2005). The ethic of care in teaching: An overview of supportive literature, Quest, 57(4), 392-425. https://doi:10.1080/00336297.2005.10491864

Shariff, S. (2005). Cyber-dilemmas in the new millennium: School obligations to provide student safety in a virtual school environment. McGill Journal of Education, 40(3), 467-478. 
Swedish National Agency for Education (2013). IT-användning och IT-kompetens $i$ skolan [ICT Use and ICT Skills in Schools]. Stockholm: Authors. Retrieved from: https:// www.skolverket.se/publikationer?id=3005

Swedish National Agency for Education (2015). Vad gör försteläraren? [What does the lead teacher do?]. Stockholm: Authors. Retrieved from: https://www.skolverket.se/publikationer?id=3423

Swedish National Agency for Education (2016a). IT-användning och IT-kompetens i skolan. Skolverkets IT-uppföljning 2015 [ICT Use and ICT Skills in Schools]. Stockholm: Authors. Retrieved from: https:/ / www.skolverket.se/ publikationer?id=3617

Swedish National Agency for Education (2016b). Curriculum for the compulsory school, preschool class and the recreation centre, 2011. Revised 2016. Stockholm: Authors. Retrieved from: https://www.skolverket.se/publikationer?id=2687

Teachers' Professional Ethics Council (2012). Teachers and social media - A statement from the Teachers' Professional Ethics Council. Retrieved from: http://www.lararesyrkesetik.se

Thunman, E., \& Persson, M. (2013). Teachers' access to and use of ICT: an indicator of growing inequity in Swedish schools. Contemporary Educational Technology, 4(3): 155-171. Retrieved from: http://www.cedtech.net/articles/43/431.pdf

Thunman, E., Lovén, J., \& Persson, M. (2016). Nationella kartläggning av lärares (åk7-9) användning av sociala medier för elevkontakter. [National survey of secondary teachers' use of social media for pupil contact]. Uppsala University: Department of Sociology.

Thunman, E., \& Persson, M. (2017). Ethical dilemmas on social media: Swedish secondary teachers' boundary management on Facebook. Teacher Development, 22(2): 175-190. http://dx.doi.org/10.1080/13664530.2017.1371634

Tirri, K., \& Husu, J. (2002). Care and responsibility in 'the best interest of the child': Relational voices of ethical dilemmas in teaching, Teachers and Teaching, 8(1), 6580. https:// doi:10.1080/13540600120110574

Ybarra, M. L., \& Mitchell, K. J. (2008). How risky are social networking sites? A comparison of places online where youth sexual solicitation and harassment occurs. Pediatrics, 121(2), 350-357. https://doi:10.1542/peds.2007-0693

Yilmaz, H. (2010). An examination of preservice teachers' perceptions about cyberbullying. Eurasia Journal of Mathematics, Science and Technology Education, 6(4), 263-270. https://doi.org/10.12973/ejmste/75248 